Iraqi Journal of Industrial Research (IJOIR)

Journal homepage: http://ijoir.gov.iq

\title{
Evaluation the Biological Activity of Nano- Gentamicin Prepared and Characterization of Nanoparticles
}

\author{
${ }^{1}$ Rana A. Kamal*, ${ }^{2}$ Quraish A. Kahdhum, ${ }^{1}$ Awatif I. Mohammed, ${ }^{1}$ Ahmed J. Essa, ${ }^{3}$ Maan A. Abd Elhamid, \\ ${ }^{1}$ Essraa A. Mohamad \\ ${ }^{1}$ Veterinary Drug Center/ Corporation of Research and Industrial Developmental - Iraq \\ ${ }^{2}$ Chemical \& Petrochemical Research Centre/ Corporation of Research and Industrial Development - Iraq \\ ${ }^{3}$ National Center for Packing and Packaging/ Corporation of Research and Industrial Development - Iraq
}

Article information

Article history:

Received: September, 14, 2021

Accepted: October, 11, 2021

Available online: October, 20, 2021

Keywords:

Sol-gel,

Bacteria,

Nanogentamycin

*Corresponding Author:

Rana A. Kamal

ranakamal_iraq@yahoo.com

DOI:

https://doi.org/10.53523/ijoirVol8I2ID79

\begin{abstract}
Gentamycin is a broad-spectrum antibacterial against Gram-positive and Gram-negative bacteria. Gentamycin Sulfate is a white powder that is freely soluble in water and insoluble in alcohol, acetone, chloroform and ether. The study aims to determine the characterization and the biological activity of gentamicin in the Nano-form prepared by Sol-gel application using an ultrasound device by aqueous solution at temperature of $80^{\circ}$. Nano gentamycin examined by Scanning electron microscopy (SEM), transmission (TEM) and the antibacterial effect test of both Nano and stander gentamycin were analyzed. The results showing that the average size of gentamycin nanoparticles is 68.51 nanometers with homogeneous distribution. The antibacterial effect of Nano gentamycin take a wide inhibition range of Gram-positive and Gram-negative bacteria compared to the standard substance, the inhibition diameters are for E. coli $(29 \mathrm{~mm})$ and for St. epidermidis (27 $\mathrm{mm})$. In the other side the inhibitory ability for standard gentamicin for St. epidrmidis and E. coli were $18 \mathrm{~mm}$ and $20 \mathrm{~mm}$, respectively.
\end{abstract}

\section{Introduction}

Gentamycin Sulphate: the antibiotic Gentamycin, which is an antibiotic has activity against gram-negative and gram-positive and gram-positive bacteria. Gentamycin it is an antibiotic belonging to the family of aminoglycosides, which is a mixture of sulphate microbial substances produced from the growth of bacteria Micromonospora purpurea. They are gentamycin C1, C1a, C2, C2a, Cb. Gentamycin Sulphate is a white powder that is freely soluble in water and insoluble in alcohol, acetone, chloroform and ether and is a broad-spectrum bacterial antibiotic (except for anaerobic bacteria and streptococcus) [1]. It is involved in the reversible binding of the $\mathrm{S} 30$ ribosome unit, as it works to inhibit the formation of the mRNA complex, thus leading to preventing protein synthesis, which results in the death of the bacterial cell [2].

Sol - gel technology: The name sol-gel is derived from the fact that the micro-particles or molecules in a solution (sol) agglomerate and under controlled conditions finally bond together to form a cohesive network (gel). There are two types of the sol-gel technique: the first type is called the colloid method, and the second type Polymeric 
method [3]. Both types include dissolving or suspending substances in a suitable liquid, usually the water in the colloidal type and alcohol in the polymeric type, so that the active substances interact together to form the gel and the gel grows over time and heat and also the volume of the container. At this point, the viscosity of the liquid will increase until it reaches to gel state [4].

Sol - gel technology has many advantages that made it used instead of other technologies [5], including: It can be operated or sterilized at high temperatures, it does not swell or shrink when in contact with liquids, it is more resistant to corrosion and Low costs.

The application of the antibiotic nanoparticle mechanism has been shown to provide several advantages over conventional administration and methods, including the ability to deliver the drug to a specific site in the cells of the body [6,7]. The nanoparticles can also be exploited to facilitate the continuous release of the antibiotic and to reduce the amount and the number of doses. Moreover, nanoparticles can block the drug inside the body, which reduces the systemic toxicity caused by conventional administration of the drug. The present study aims to evaluate the bioactivity of gentamicin Nano-prepared [8].

\section{Experimental Procedure}

\section{Preparation of Gentamicin Nano Sol-Gel Method}

Prepare nanoparticles by using the Sol gel method, which is the simplest method by reducing the particle size. Preparation of nano gentamicin, in brief: gel of gentamicin was prepared as follows:0.01g of gentamicin sulfate was dissolved in $400 \mathrm{ml}$ of distilled water, then $600 \mathrm{ml}$ of ethanol was added slowly at $50^{\circ} \mathrm{C}$, and $6 \mathrm{ml}$ of $\mathrm{CH} 3 \mathrm{COOH}$ $(47 \%)$ was added drop wise then mixed to get clear solution and at a temperature of $80^{\circ}$ using the Probe Sonicator as a catalyst and a hydrolysis agent that transforms the material in the final stage with increasing temperature's solution into the Nano form [9].

\section{Characterization Measurement of Nano- Gentamicin Atomic Force Microscopy}

To observe the surface roughness and topography of the sedimentary thin films, they are examined with a Scanning Probe Microscope (SPM), which was examined at Baghdad University / College of Science [10]. Scanning Electron Microscopy (SEM)

\section{Scanning Electron Microscope}

A scanning electron microscope is used to view the nanostructures and examine the surface morphology of the samples, as the samples were examined with a scanning electron microscope Inspect S50 with a magnification power of (X2000) at CAC Lab.

\section{Transmission Electron Microscopy (TEM)}

The transmission electron microscope is used to understand the properties and size of nanoparticles. Testing was performed with a Tecnai G2 20 at $200 \mathrm{kV}$ at CAC Lab.

\section{Biological Activity Test}

The bacteriological assay of gentamycin nanoparticles gel was performed by using two kinds of bacteria Staphylococcus epidrmidis and Escherichia coli were obtained from the culture collection of Veterinary Drug Center, Ministry of Industry and Minerals, (Baghdad, Iraq). The antibacterial Susceptibility assay was used to detect the inhibitory effect of gentamycin against the negative and positive Gram-positive bacteria. By using the Agar Muller-Hinton culture medium, $1 \mathrm{ml}$ of the bacterial suspension was spread and the plates were left at room temperature for 15 minutes after which the Holes were drilled in the culture medium inoculated with bacteria with a sterile perforator with a diameter of $7 \mathrm{~mm}$, and by a fine mechanical pipette, transferred $50 \mu \mathrm{l}$ of the gentamicin solution placed inside the tips, then the dishes were incubated at $37^{\circ} \mathrm{C}$ for $18-24$ hours, then the results were taken by measuring the diameter of the inhibition area, which represents the area Non-growth of bacteria surrounding the hole with a ruler [11]. 
NANO 2021

Special Issue

Iraqi Journal of Industrial Research, Vol. 8, No. 2 (2021)

3. Results and Discussion

Characterization of Nano - Gentamicin

Atomic Force Microscopy (AFM)

The surface characteristic of gentamicin nanoparticles was determined by atomic force microscopy (AFM). The average surface roughness is $4.02 \mathrm{~nm}$, the increased in surface roughness of gentamicin nanoparticles will enhance light absorption in photodetector applications and the highest grain size is $17 \mathrm{~nm}$ were obtained by using (AFM) test, showing the homogeneous cumulative distribution of gentamicin nanoparticles and the different grain size in the Nano gel, as shown in Table (1) and Figure (1). The results showed that the average diameter of gentamycin particles was $68.51 \mathrm{~nm}$.

Table (1). Different size of gentamicin nanoparticles in the Nano gel

\begin{tabular}{|c|c|c|c|c|c|c|c|c|}
\hline \multicolumn{3}{|c|}{$\begin{array}{l}\text { Avg. Diameter:68.51 nm } \\
<=50 \% \text { Diameter:65.00 nm }\end{array}$} & \multicolumn{6}{|c|}{$\begin{array}{c}<=10 \% \text { Diameter:0 } \mathrm{nm} \\
<=90 \% \text { Diameter:80.00 nm }\end{array}$} \\
\hline $\begin{array}{l}\text { Diameter }(\mathrm{n} \\
\mathrm{m})<\end{array}$ & $\begin{array}{c}\text { Volume } \\
\%)\end{array}$ & $\begin{array}{c}\text { Cumulation } \\
(\%)\end{array}$ & $\begin{array}{l}\text { Diameter }(\mathrm{n} \\
\mathrm{m})<\end{array}$ & $\begin{array}{c}\text { Volume } \\
\%)\end{array}$ & $\begin{array}{c}\text { Cumulation } \\
(\%)\end{array}$ & $\begin{array}{l}\text { Diameter }(\mathrm{n} \\
\mathrm{m})<\end{array}$ & $\begin{array}{c}\text { Volume } \\
\%)\end{array}$ & $\begin{array}{c}\text { Cumulation } \\
(\%)\end{array}$ \\
\hline 55.00 & 10.27 & 10.27 & 70.00 & 15.07 & 57.53 & 85.00 & 13.01 & 93.15 \\
\hline 60.00 & 16.44 & 26.71 & 75.00 & 13.70 & 71.23 & 90.00 & 3.42 & 96.58 \\
\hline 65.00 & 15.75 & 42.47 & 80.00 & 8.90 & 80.14 & 95.00 & 3.42 & 100.00 \\
\hline
\end{tabular}

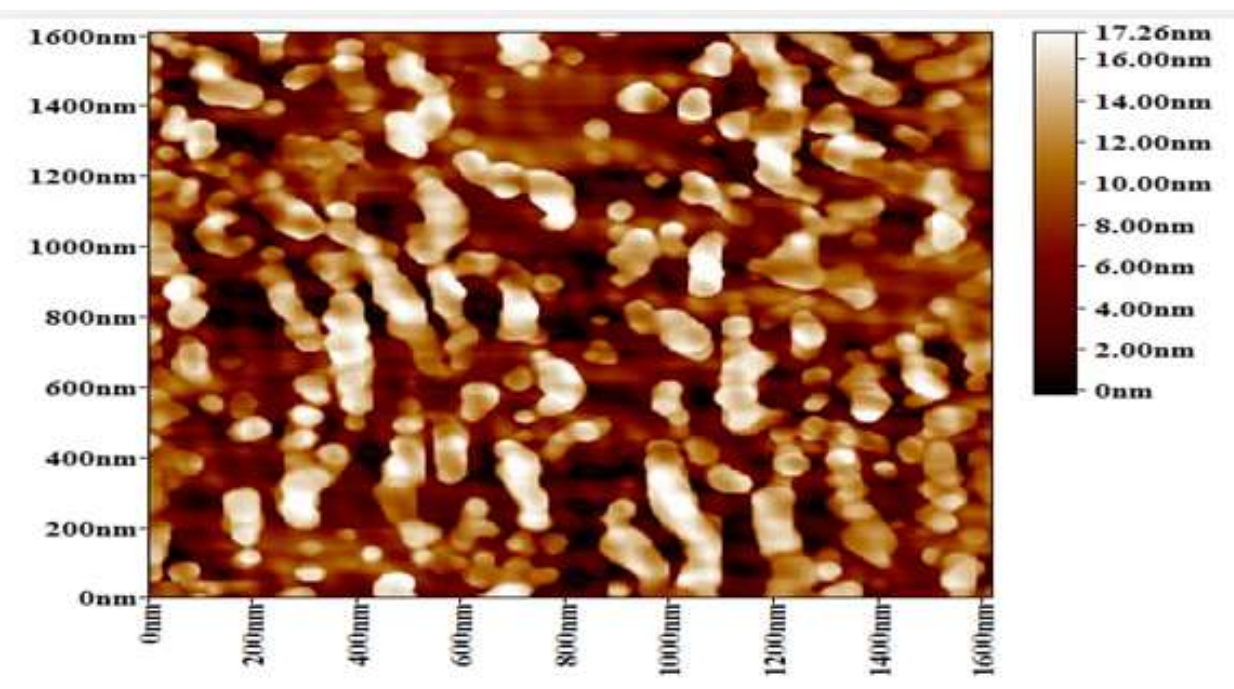

Figure (1). AFM image Cumulative homogeneous distribution of CSPM-tested nanoparticles of gentamicin.

\section{SEM and TEM Electron Microscope}

The SEM assay confirmed that the gentamicin particles reached the nanoparticle shape and size. The test also showed four dimensions of the gentamicin nanoparticle ranging from (19-31) nm. The gentamicin particles are relatively spherical and uniformly shaped particles as shown in Figure (2). There was a minimal amount of particle clumping as well. Agglomeration is a phenomenon that arises from the sticking of particles together one after the other. The reason for this is that gentamicin has a hydrophilic nature; Inevitably traces of water remain inside the particle or near the surface [12]. This is consistent with AFM test. The samples were examined with an EDX device attached to a scanning electron microscope, through which the quality and quantity of elements present in each sample as shown in Figure (3) and the peaks of cadmium and calcium were observed in the Figure as well as oxygen that served as a cover for the nanoparticles. The result of the TEM assay confirmed the surface roughness of the gentamycin nanoparticles and the homogeneous cumulative distribution. 

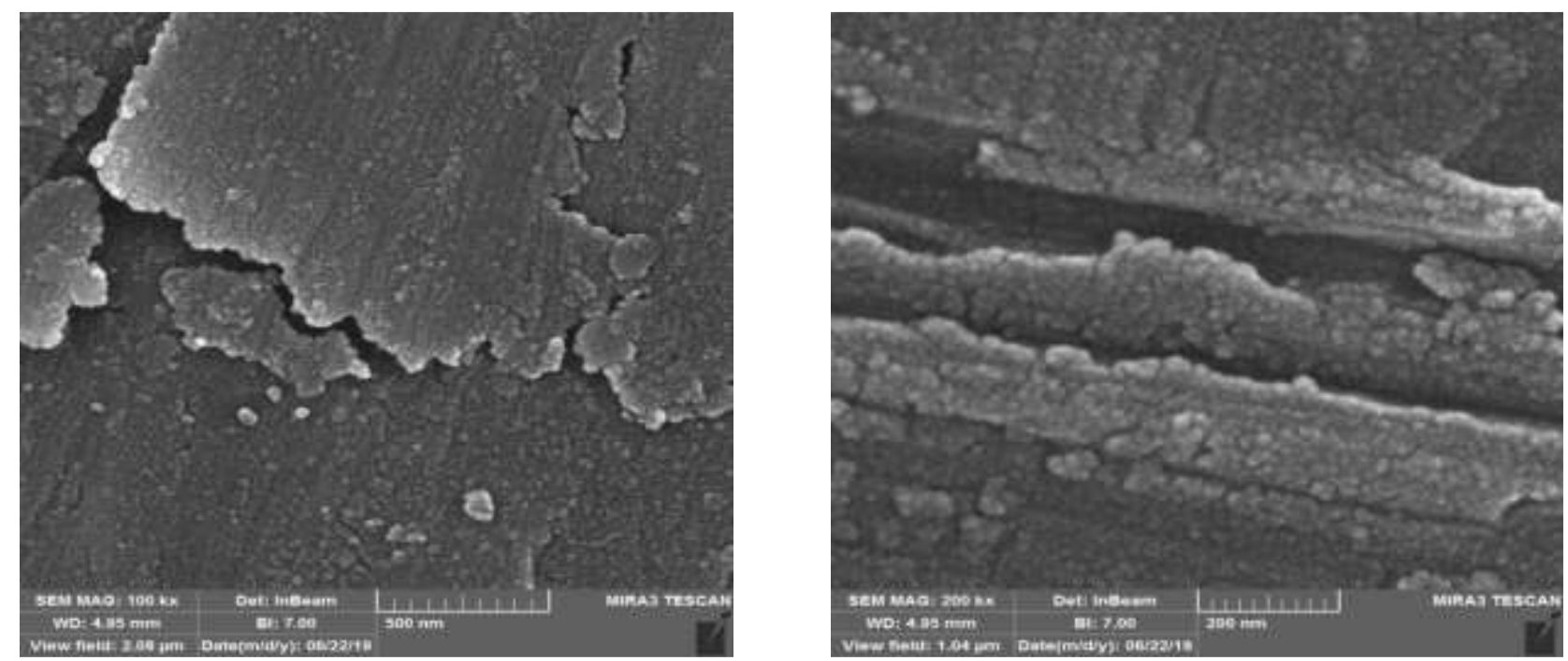

Figure (2). Shows the SEM images of gentamicin nanoparticles.

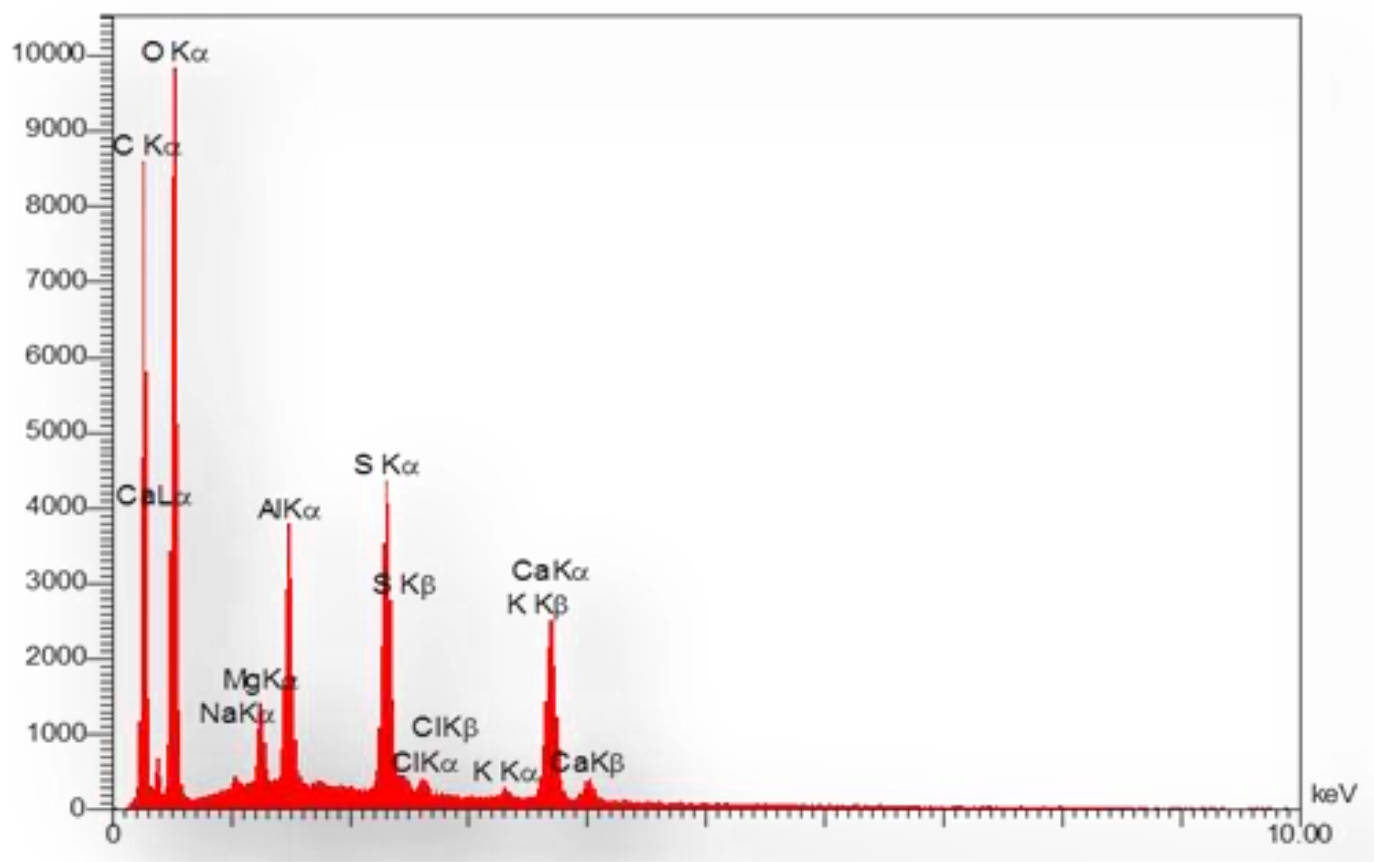

Figure (3). Shows the EDX pattern of gentamicin nanoparticles.

It is important, since surface roughness plays a major role in controlling the initial release of antibiotics, as rough surfaces establish a larger area for antibiotic release [13]. The transmission electron microscope is a good tool for confirming the structure and shape of materials. The images taken with (TEM) showed that the nanoparticles of gentamycin are spherical, uniformly distributed and have a rough surface as shown in Figure. (4) 


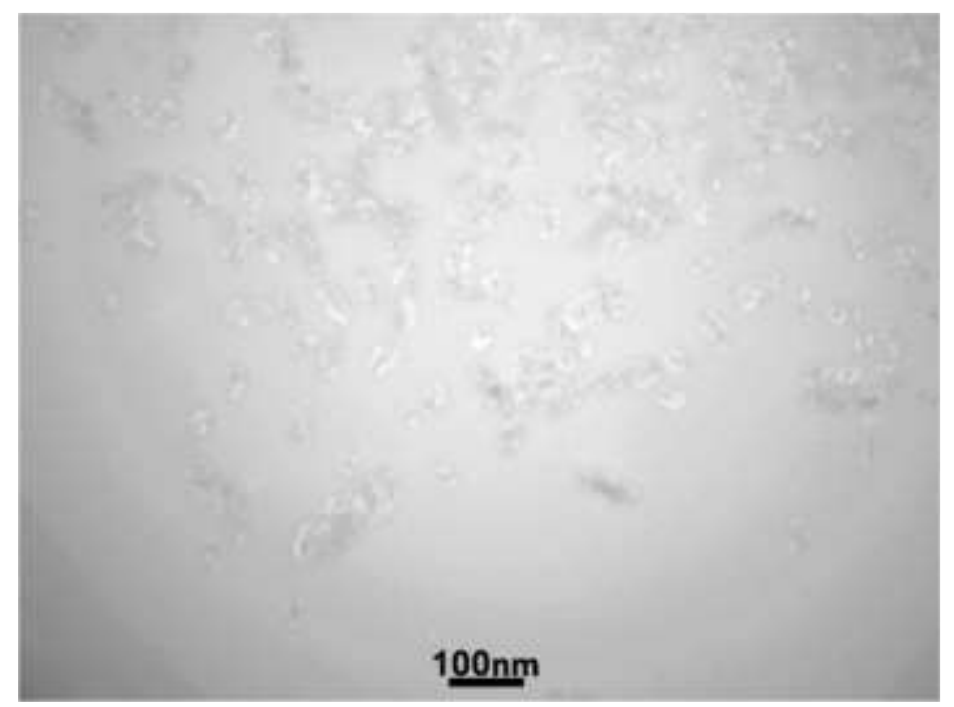

Figure (4). Shows (TEM) image of gentamycin nanoparticles.

\section{Biological Activity Test}

The bacteriological assay of gentamycin nanoparticles gel was performed by using two kinds of bacteria Staphylococcus epidrmidis and Escherichia coli were obtained from the culture collection of Veterinary Drug Center, Ministry of Industry and Minerals, (Baghdad, Iraq), from Figure. (5) The clear zone represent the inhibition zone (no bacterial growth). The nanoparticle gel showed super inhibitory ability as show in Figure. (5), the diameters of inhibition for St. epidrmidis and E. coli, were $27 \mathrm{~mm}$ and $29 \mathrm{~mm}$, respectively and that is due to their different cell walls. In the other side the inhibitory ability for standard gentamicin for St. epidrmidis and E. coli were $18 \mathrm{~mm}, 20 \mathrm{~mm}$ respectively as shown in Figure. (5) And as shown in table (2). The zone S means standard gentamicin and the zone $\mathrm{T}$ means gentamycin nanoparticles. The reasons for the inhibitory ability of gentamycin nanoparticles higher than the inhibitory ability of standard gentamicin due to the Nano encapsulation gentamicin enhances its cellular accumulation and improves its effectiveness against intracellular bacteria [14] and also due to nanoparticles structures, and the antibacterial activity increased with increasing the anti-biotic content [15].

Table (2). A Comparative between the biological activity of Standard gentamicin and nano gentamicin.

\begin{tabular}{|c|c|c|}
\hline $\begin{array}{c}\text { Sabstans / Concentrations } \\
\text { mg\ml }\end{array}$ & E.coli & St. epidrmidis \\
\hline Standard gentamicin 0.01 & $20 \mathrm{~mm}$ & $18 \mathrm{~mm}$ \\
\hline Nano gentamicin 0.01 & $29 \mathrm{~mm}$ & $27 \mathrm{~mm}$ \\
\hline
\end{tabular}




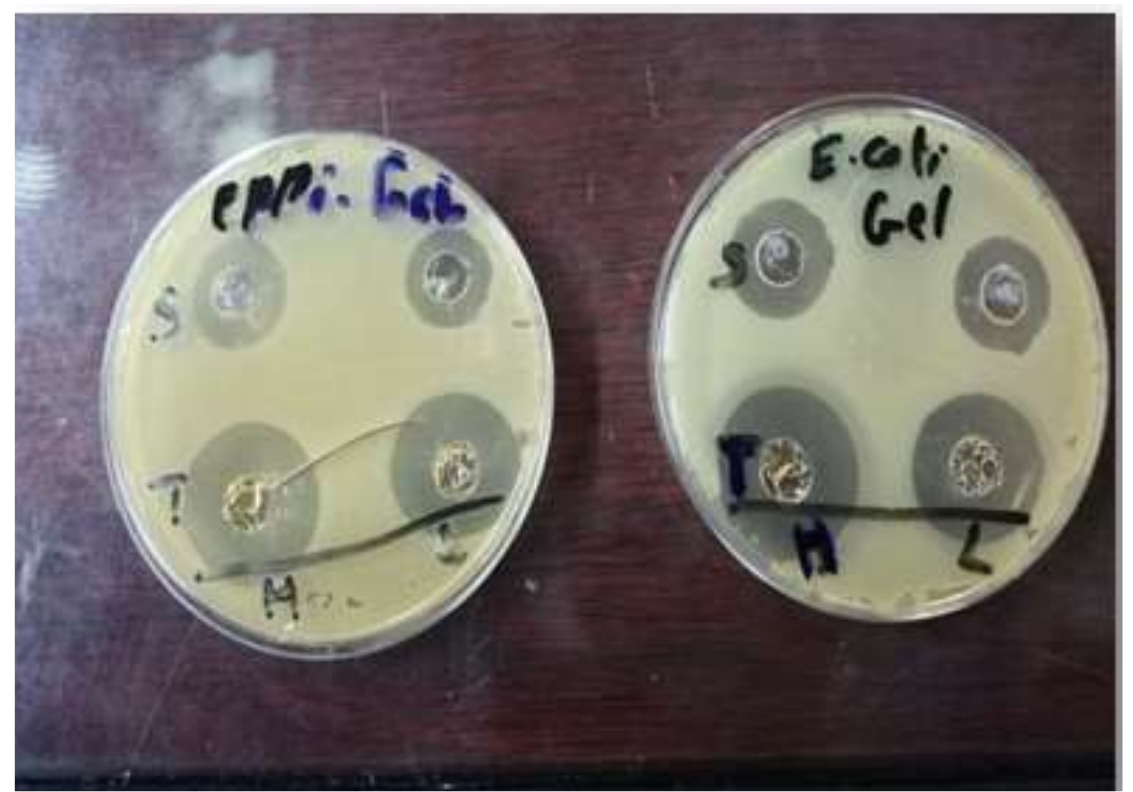

Figure (5). Inhibitory activity of gentamycin nanoparticles and Standard gentamicin in E. coli \& St. epidermidis.

\section{Conclusions}

The antibiotic Gentamicin transform successfully to the Nano form with the average grain size $68.51 \mathrm{~nm}$ with using Sol- gel method. AFM, SEM \& TEM tests confirm that is the Nano-Gentamicin particles have the surface roughness and the homogeneous distribution. The biological activity of Nano-Gentamicin was super than the biological activity of standard Gentamicin.

Acknowledgement: All the authors are thank Dr. Ahmed Younis, Director General of Corporation of Research and Industrial Development, for his directive guidance and great assistance in carrying out the research.

\section{References}

[1] K. T. Fitzgerald, and K. L. Newquist "Poisonings in the Captive Reptile in Small Animal Toxicology," 3rd.ed., Michael E. Peterson and Patricia A., 2013.

[2] S. M. Abdelghany, D. J. Quinn, R.J. Ingram, B. F. Gilmore, R. F. Donnelly, et al., "Gentamicin-loaded nanoparticles show improved antimicrobial effects towards Pseudomonas aeruginosa infection", Int $J$ Nanomedicine, vol.7, p. 4053-4063, 2012.

[3] D. Ficai, A. Grumezescu, "Nanostructures for Novel Therapy Synthesis, Characterization and Applications" ,1st ed., Matthew Deans, 2017.

[4] A.Hamdy , A. Barhoum "Emerging Applications of Nanoparticles and Architecture Nanostructures", 1st ed., Mathew Deans, 2018.

[5] S, Seyed," Sol-gel process and its application in Nanotechnology", Journal of Polymer Engineering and Technology, vol. 13, pp 38-41, 2005.

[6] H. Pinto, A. Andremont, and P. Couvreura," Targeted delivery of antibiotics using liposomes and nanoparticles": research and applications, Int J Antimicrobial Agents, vol.13, p155-168, 2000.

[7] C. R. Thorn, N. Thomas, B. J. Boyd, and C. A. Prestidge" Nano-fats for bugs: the benefits of lipid nanoparticles for antimicrobial therapy", Springer Nature, vol.11, p1598-1624, 2021.

[8] M. H and A. T, "Amoxicillin-Loaded Polymeric Nanoparticles of Less than $100 \mathrm{~nm}$ : Design, Preparation and Antimicrobial Activity Against Methicillin-Resistant Staphylococcus aureus", Iranian Journal of Science and Technology, vol. 43, p 379-386, 2019.

[9] A. Hatim, A.AbdUljaleel, and S.Oudah, , "Synthesis and Characterization of Silica Nanoparticle $\left(\mathrm{SiO}_{2} \mathrm{Nps}\right)$ Via Chemical Process, Annals of R.S.C.B., vol. 25, p. 6211 - 6218,2021

[10] S. A. Kumar and S. M.Chen," Nanostructured Zinc Oxide Particles in Chemically Modified Electrodes for Biosensor Applications", Analytical Letters, vol. 41, p. 141-158, 2008. 
[11] T. Jumaa, M. Chasib, M. K. Hamid, and R. Al-Haddad," Effect of the Electric Field on the Antibacterial Activity of Au Nanoparticles on Some Gram-positive and Gram-negative Bacteria" Science and Education, vol. 2, p. 1-7, 2014.

[12] D. Ahmed, Y.Ge, M. Gasik, K. Nordström, O.Natri, et al .," Silica-Gentamicin Nanohybrids: Synthesis and Antimicrobial Action", Materials (Basel), vol.9, p. 170, 2016.

[13] H. van de Belt, D. Neut, D. R. Uges, W. Schenk, et al., "Surface roughness, porosity and wettability of gentamicin-loaded bone cements and their antibiotic release, Biomaterials, vol. 19, p. 1981-7, 2000.

[14] E. Imbuluzqueta, S. Lemaire, C. Gamazo, E. Elizondo, N. Ventosa, et al.," Cellular pharmacokinetics and intracellular activity against Listeria monocytogenes and Staphylococcus aureus of chemically modified and nanoencapsulated gentamicin", J. Antimicrob Chemother, vol. 67, p. 2158 -2164, 2012.

[15] H. M. Ibrahim, M. K. El-Bisi, G. M. Taha, and E. A. El-Alfy," Chitosan nanoparticles loaded antibiotics as drug delivery biomaterial “, Journal of Applied Pharmaceutical Science, vol.5, p. 85-90, 2015. 